\title{
A Spatial Perspective to the Distribution of Healthcare Facilities and Health Personnel in the Eastern Region of Ghana
}

\author{
Stephen Manortey, Gideon Kwarteng Acheampong \\ Ensign College of Public Health, Kpong, Ghana \\ Email: steve.manortey@ensign.edu.gh, gideonacheampong@st.ensign.edu.gh
}

Received 6 August 2016; accepted 26 August 2016; published 29 August 2016

Copyright (C) 2016 by authors and OALib.

This work is licensed under the Creative Commons Attribution International License (CC BY). http://creativecommons.org/licenses/by/4.0/

(c) (i) Open Access

\begin{abstract}
Background: A major factor for health services provision in various communities is the concern for spatial justice in the distribution of healthcare facilities. The eastern region with most of its population in rural areas has been subject to frequent increases in the number of administrative districts over time. This however has not correspondingly followed with a significant increase in the number of health facilities and health personnel in the region, a phenomenon that has disturbed the distribution of health facilities and personnel, thus the purpose of this study to investigate the spatial pattern in the distribution of health facilities and health personnel. Methods: Data on the global positioning system of each health facility and the total number of health workers were factored with the population in the administrative districts of the eastern region as part of analysis to investigate the distribution of health facilities and health personnel per population of each district and the Region. Results: Health facilities and health personnel were unevenly distributed, recently added districts such as Kwahu Afram Plains South, Ayensuano, Upper West Akim along with existing ones such as Birim South, Kwahu West, Akyem Mansa, and Kwahu East all lacked in terms of health facilities and health personnel. Conclusions: This observed deficiency in distribution of health facilities and health personnel has the potential to generate productivity inequalities among residents of the Eastern Region which in turn has a negative effect on the entire development of the region. Areas that were identified as disadvantaged districts should be considered for various intervention strategies.
\end{abstract}

\section{Keywords}

Health Facilities, Health Personnel, Districts, Municipalities

Subject Areas: Natural Geography, Public Health

How to cite this paper: Manortey, S. and Acheampong, G.K. (2016) A Spatial Perspective to the Distribution of Healthcare Facilities and Health Personnel in the Eastern Region of Ghana. Open Access Library Journal, 3: e2956.

http://dx.doi.org/10.4236/oalib.1102956 


\section{Introduction}

The ultimate goal of primary health care is better health for all, which includes accessibility, equity and affordability of healthcare as adopted in the declaration of the international conference on primary health care in Alma Ata, Russia in 1978 [1]. A 2008 WHO report argued that substantial progress in health has been largely differential worldwide with convergence towards improved health in large parts of the world. A considerable number of countries are increasingly lagging behind coupled with growing health inequalities within countries [1]. According to the concepts of the principles of equity and health, equity in health care is based on the principle of making high quality health care accessible to all [2]. Underpinning most health care systems is the belief that there should be a fair and equitable deployment of available resources for the benefit of a whole population. Health services should be based on equal expenditure per capita; by this definition an equitable allocation would be achieved if the available health service budget were divided equally amongst geographical areas based on the size of population in each area [2]. Access to health care is an important predictor of the overall success of a healthcare delivery system and has a direct impact on disease burden especially in the developing world. This has been also shown to positively influence health systems in various populations [3]. Measuring accessibility to health care thus contributes to a wider understanding of health system performance [4] [5]. Unfortunately health care services is not equally accessible to all people and continues to be a major barrier to achieving the goal of health care for all and sundry [6]. Atser and Akpan (2009) reported that variation in distribution of facilities is crucial especially in rural areas where there are problems of limited facilities and low mobility of health personnel [7]. Results from a study in Ondo State showed that healthcare facilities in the state were unevenly distributed, hence hampering health development at the grassroots [8]. Adedayo and Yusuf in a study on health deprivation in rural states in Borno, Nigeria [9] concluded that health deprivation is a disturbing phenomenon which hampers quality of life among rural settlements. The implications of the mal-distribution of health facilities manifest in overcrowding, a consequent lack of proper attention to patients as well as poor access in some specific areas with vulnerable conditions of low number of health facilities especially among the rural dwellers [10]. Equitable access to primary health care is a key objective to health policy makers. Healthcare workers as well should be accessible for all people in the farthest and poorest parts of a country.

In Ghana, the Eastern Region has been subject to frequent increases in the number of administrative districts over time [11]. A report of the committee on district boundaries sighted issues such as divergence between traditional and administrative boundaries, lack of updated and authentic maps, lack of collaboration between implementing agencies, growth and disappearance of settlements, interventions from politicians and opinion leaders as reasons behind continuous district disputes and subsequently further creation of district boundaries [11]. The initial 17 districts were increased to 21 in 2007 and from 21 to 26 in 2012 [12]. This however has not correspondingly followed with a significant increase in the number of health facilities and health personnel within districts in the region, an occurrence that has affected the overall health status especially in the rural areas, this mainly owing to the fact that there are rural-urban inequalities with regard to health facilities [13]. A 2011 annual health report of the Eastern region reported that, community based health planning services (CHPS) had been in a terrible state. A number of districts such as the then Kwahu North (now Kwahu Afram Plains North and South) and Akwapim South (Now Nsawam Adoagyiri, Ayensuano and Suhum Kraboa), New Juabeng, Upper Manya, Birim South and Asuogyaman recorded huge deficits in the number of CHPS compounds which in turn had a huge effect on access to health care facilities by residents in rural settings. Residents who found themselves in these geographical areas had to travel over $8 \mathrm{~km}$ to access health care [13], a phenomenon in clear violation of the WHO recommended standards for the proximity of health facility to residents which states that health facilities should not be situated more than $5 \mathrm{~km}$ from a residential area [1].

Thus the purpose of this study is to assess the distribution patterns in relation to the population of the region [13]. The specific objectives of the study include: examining the spatial distribution of health facilities versus the human population across districts/municipalities of the region, to examine the distribution of healthcare workforce among population, to determine the relationship between the number of health facilities and the population as well as the relationship between number of healthcare workforce and population.

\section{Study Site}

The Eastern Region of Ghana shares boundaries with the Greater Accra, Central, Ashanti, Brong Ahafo and Volta Regions of the country as displayed in Figure 1, the region covers a total land area of 19,323 sq. km and 


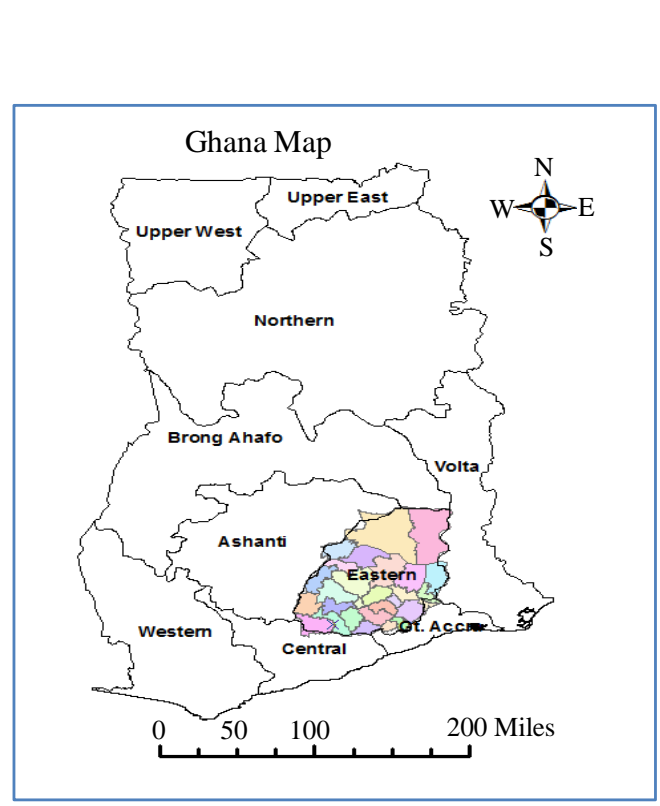

(a)

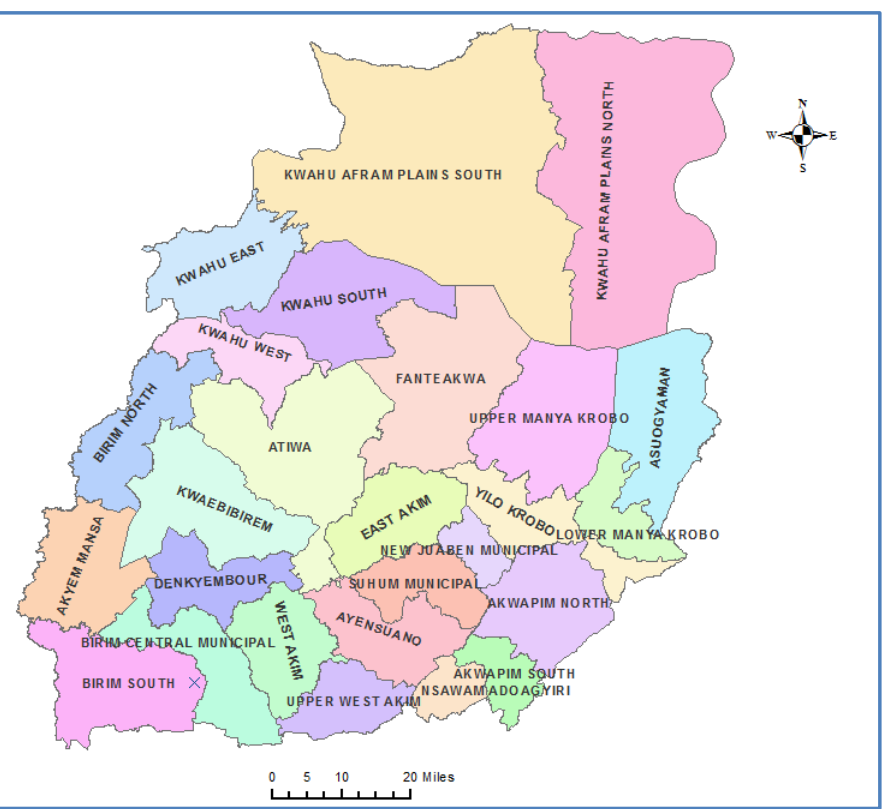

(b)

Figure 1. (a) Map of Ghana showing geo-political zones; (b) Map of the Eastern region showing various districts/municipalities [14].

has a population density of 136.3 people per sq. $\mathrm{km}$. The population of this region increased from 1,635,421 in 2000 to 2,633,154 in 2010. With a growth rate of $2.1 \%$, the population is expected to increase approximately to 4.5 million by 2040. In 2012, 5 new districts were created in the Eastern region to add up to the already existing 21 to make a total of 26 districts. The 5 newly created districts were born out of some of the old existing districts, the breakdown is as follows; Kwaebibirem was formed from Denkyembour, Kwahu North has given rise to now Kwahu Afram Plains North and South, Suhum-Kraboa-Coaltar gave rise to Ayensuano district, Akwapim South gave rise to the Nsawam Adoagyiri district and the West Akim gave rise to Upper West Akim [12].

\section{Methods}

1) Data on the number and types of healthcare facilities and the number and types of health personnel across the Eastern region was used for this study and was obtained from the Eastern Regional office of the Ghana Health Service. Health facilities that were incorporated in this study were for all functional facilities in the region as at the year 2015 .

2) The study utilized-partly existing records and also generated way points from Google Map of the healthcare facilities located across the region within each administrative district or municipality.

3) The 2010 population of the Eastern region was also obtained from the Ghana Statistical service as part of items to be used for multivariate analysis.

Discussions were held with personnel of the Eastern regional division of the Ghana health service to deliberate on issues bothering on access to health care.

\section{Data Analysis}

1) The ArcGIS software (version 10.3.1) was used for all spatial analysis. STATA (version 12) was used for all univariate and multivariate analysis. Analysis was done based on set aims and objectives.

2) To explore the influence of the geo-political zones on the number of health facilities, data on the number health facilities and district population were both categorized and subjected to a chi square analysis. The dependent variable being the number of health facilities and independent variables was the resident population in every district. Pearson Correlation analysis was then applied to investigate the relationship between the population and number of health facilities as well as that between the population and the health personnel across the districts in the Eastern Region of Ghana. 


\section{Results}

A total of 587 health facilities were counted in the region, indicating a $12.5 \%$ increase in the number of health facilities from 2010, where 522 health facilities were present [15]. Again 4,859 health workers were recorded; these workers included 151—doctors, 157—physician assistants, 541—midwives and 3,754 nurses, 144pharmacists and 112-laboratory technicians. As part of activities undertaken to collect data, discussions with personnel of the Department of Health Information of the Eastern Regional Health Directorate were held and the results were summarized in the below.

1) The personnel asserted that health facilities were mostly randomly distributed in most districts however some of these facilities were placed upon request by community members.

2) Most health facilities were not placed at vantage points with only a few well positioned for ease of access by community residents. Health facilities as well happened to be more clustered in urban areas and happened to be more scattered in the rural communities.

3) In relation to access and on the question of how close health facilities were to residents it was mentioned that some facilities were located at the heart of various communities while others were situated on the outskirts of communities. However it was mentioned that community members were best positioned to provide answers to how close facilities are to residents.

4) With regard to proximity of health facilities to residents it was mentioned that community members living far from health facilities were more likely experience difficulties reaching the facility.

5) On the issue of the consequences of poor access to healthcare, it was highlighted that access problems would mean poor service coverage; more people may not be able to access health care as expected and that also means disease burden will increase due to incomplete containment of certain diseases. As part of a justification to improve healthcare, officials mentioned that when clients can easily get access to healthcare, they will most likely seek healthcare early which will improve disease control and prevention as early detection of health problems as well as early treatment is a key public health strategy.

The population distribution by district/municipalities was displayed in the Figure 2 below.

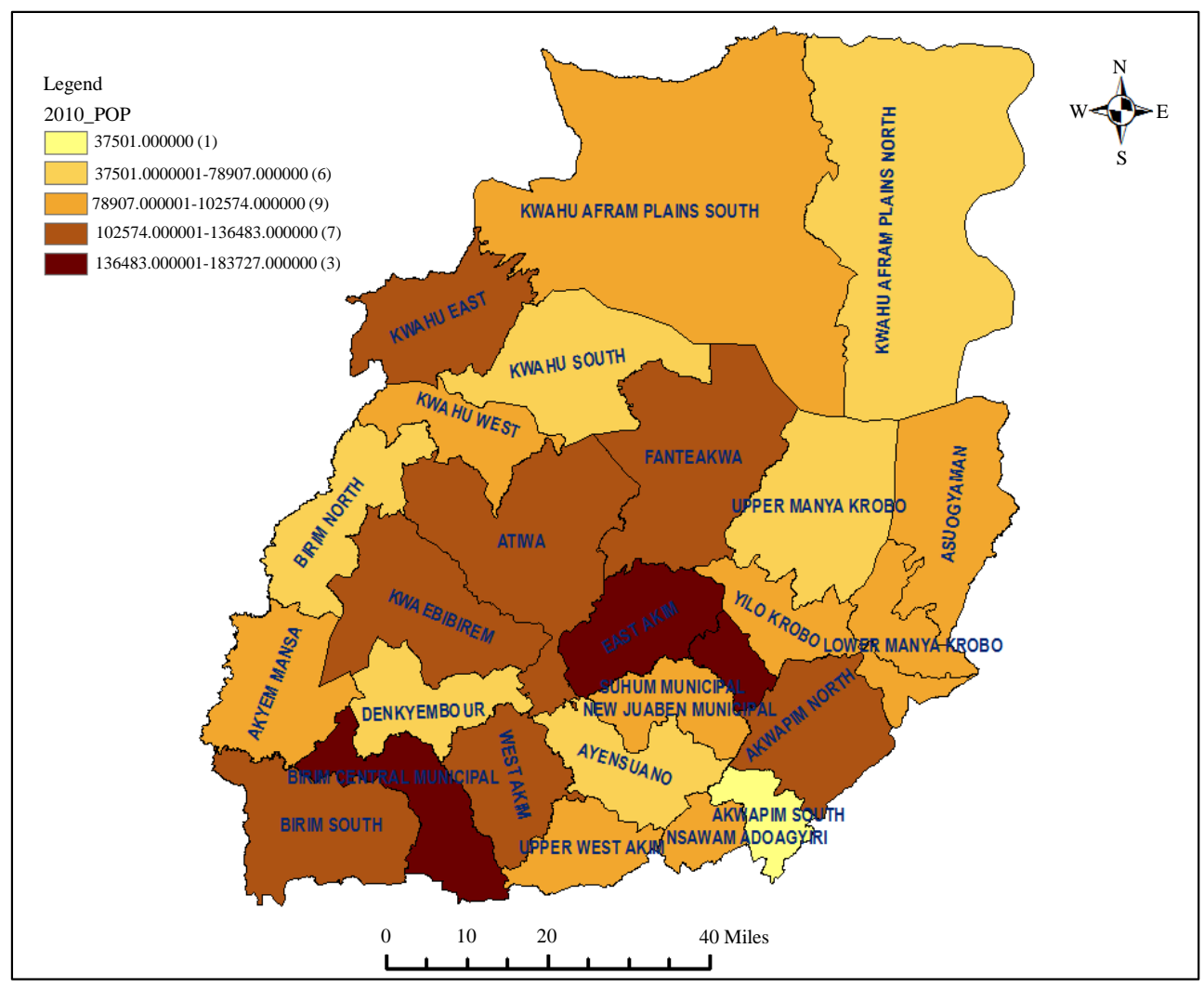

Figure 2. Population breakdown by district/municipalities in the Eastern Region of Ghana. 
Figure 2 displays the breakdown of the Eastern Region into its 26 administrative districts by population. The legend shown at the top left corner of the map shows the population in ranges arranged from the highest to the lowest, the strength of the color shade corresponds to how high or low the population is. Areas with the deep color shades represent high populations while low color shades depict low populations. As observed, the New Juabeng Municipal, Birim Central Municipal and East Akim were the districts with high resident population compared to other districts, and hence had deeper color shades.

\subsection{Distribution of Health Facilities}

\subsubsection{Distribution of Hospitals}

Figure 3 shows the spread of hospitals across the various districts. There appeared to be an overlap between these hospital facilities especially in districts with more than two or three hospitals. Districts such as Akyem Mansa, Kwahu Afram Plains South, Kwahu East, Ayensuano, Yilo Krobo and Upper West Akim did not have district hospitals neither did they have private nor mission hospitals. The spatial distribution of hospitals also seemed to be weighed more towards the southern and middle sections of the region compared to its northern section.

\subsubsection{Distribution of Clinics}

Contrary to the distribution of hospitals in the Eastern Region, the distribution of clinics took a different twist. Apart from the Ayensuano district which did not have any clinic all other districts had clinics with the district capitals of New Juabeng, West Akim and the Birim Central having the highest numbers of clinics. Majority of

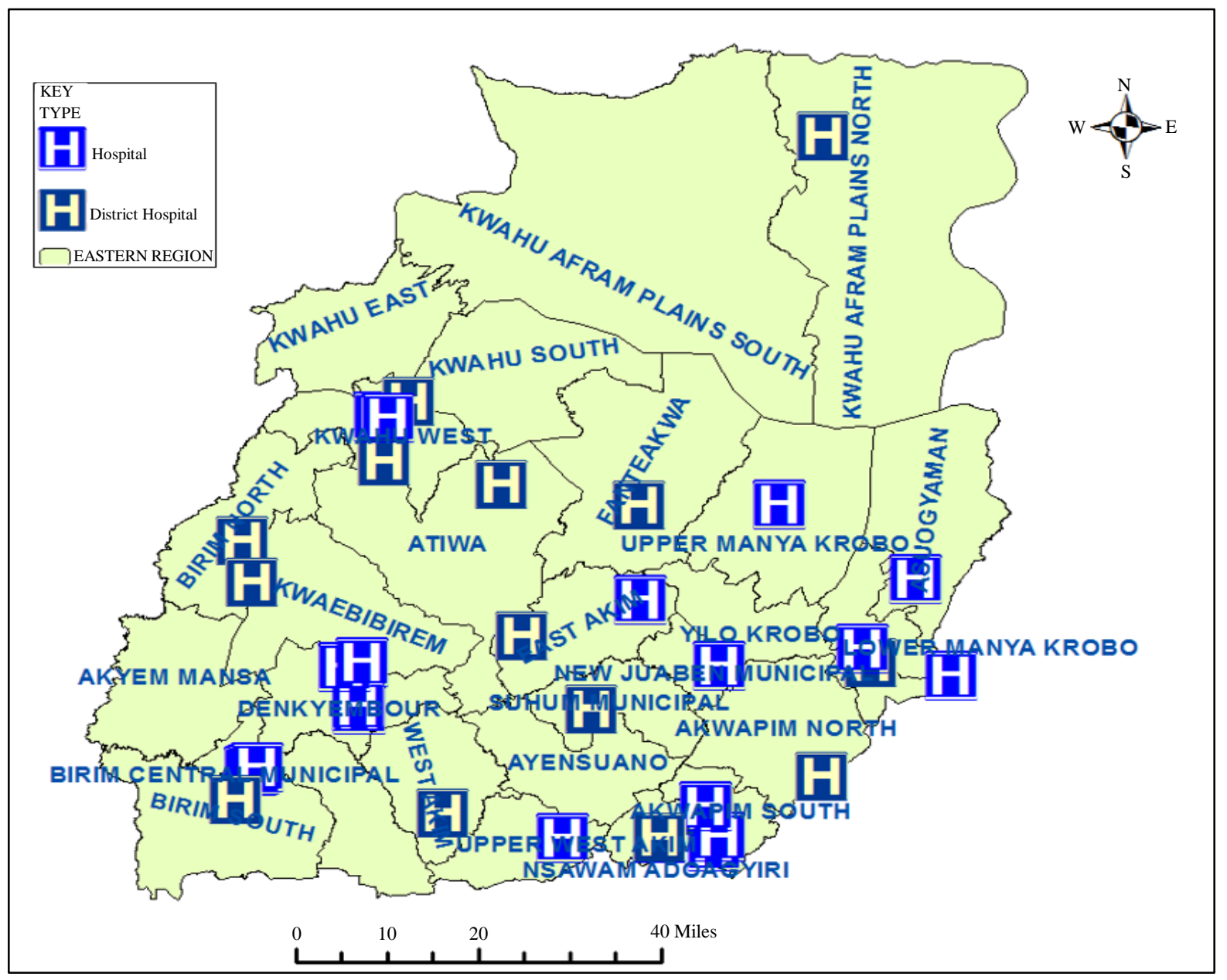

Figure 3. Map displaying distribution of hospitals in the Eastern Region of Ghana. 
the clinics were located to the more southern portions of the Region. Kwahu Afram Plains South and North had a combined total of only 2 health facilities as observed in Figure 4. A similar situation is observed with the hospital distribution with Kwahu Afram Plains North and South recording low numbers in terms of hospitals in Figure 3.

\subsubsection{Distribution of CHPS Compounds}

The distribution of CHPS compound in the Region was relatively better than that of hospitals and of clinics. Apart from the Atiwa and Kwahu West districts which did not have any record of a CHPS compound, all other districts had an average of about 8 CHPS compound. Districts in close proximity with especially Atiwa such as Kwahu South, Fanteakwa and East Akim all recorded numbers much lower than the regional average of 8 . This phenomenon is well illustrated in the Figure 5.

\subsection{Distribution of Health Personnel}

Distribution of Doctors and Physician Assistants versus Population

A hotspot analysis of the number of doctors in each district on the corresponding population of districts was

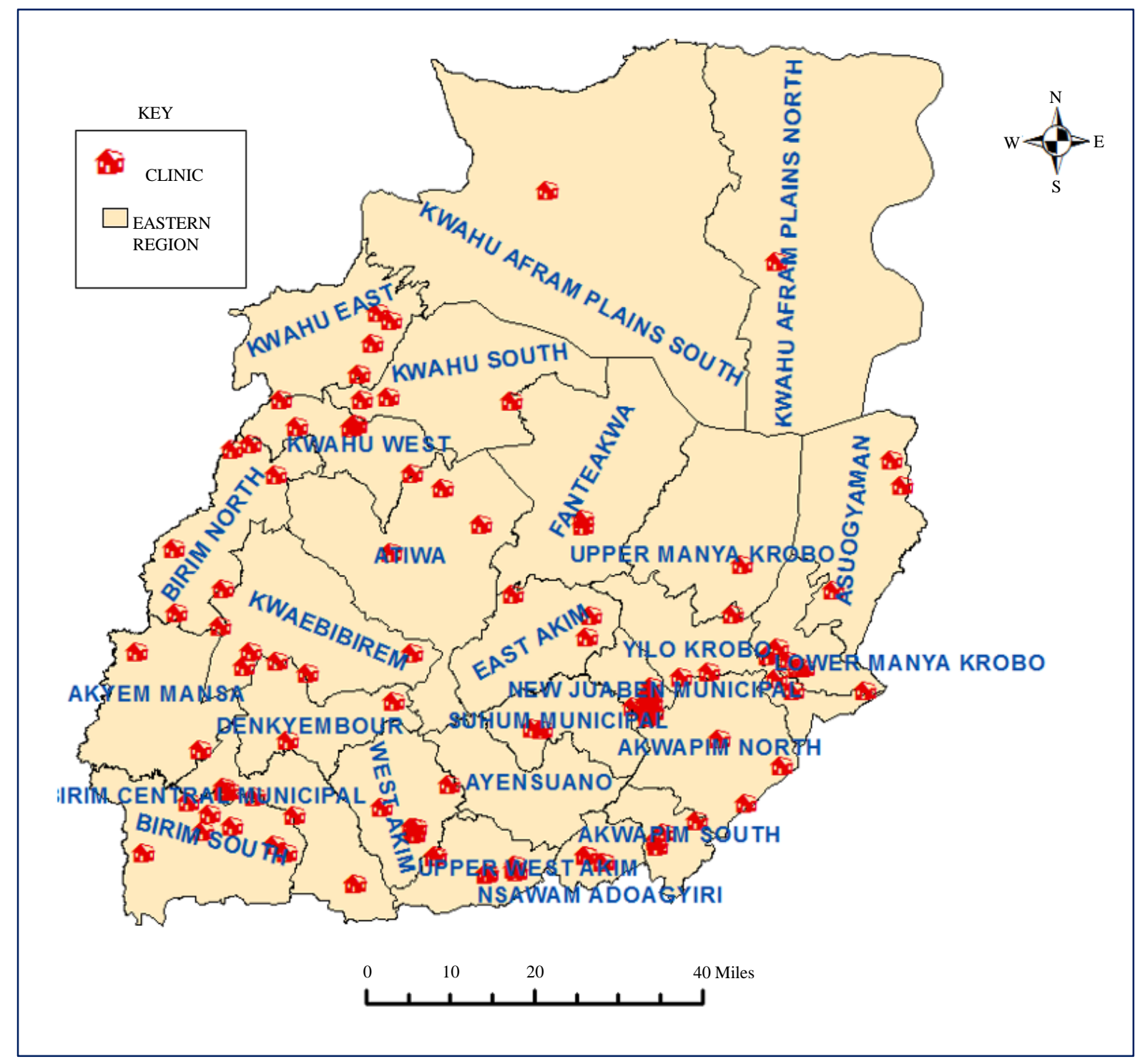

Figure 4. Map displaying distribution of clinics in the Eastern Region of Ghana. 


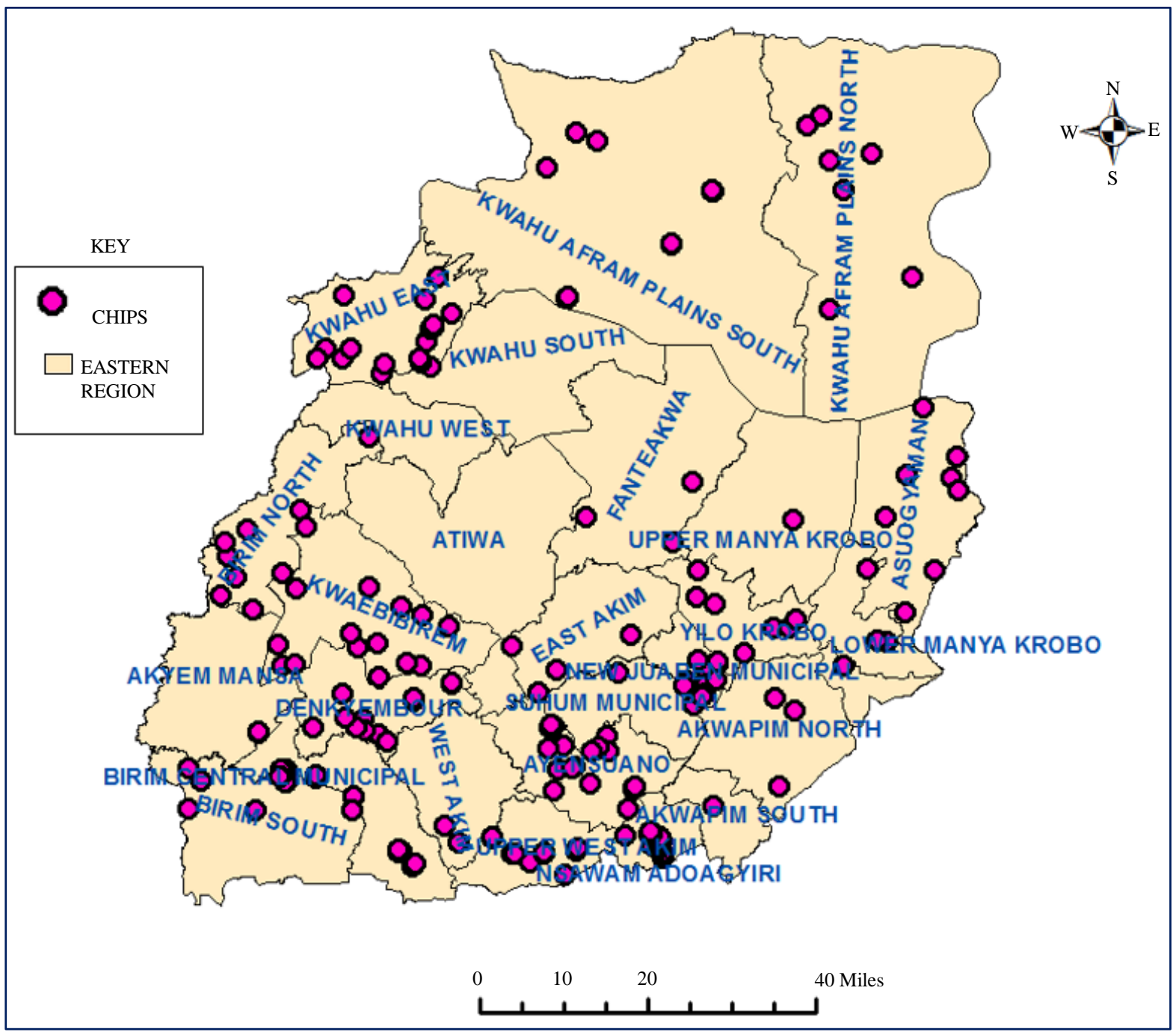

Figure 5. Map showing distribution of CHPS compound in the Eastern Region of Ghana.

conducted and the results pictorially displayed on Figure 6. The grades of color shades used represented the strength of the doctor population situation. Areas which showed darker color shades indicated districts with better doctor population ratios compared to lighter color shades. From the Figure 6, it is well observed that the New Juabeng Municipal had the best doctor-population ratio, followed by Kwahu South, Suhum, Lower Manya, Akwapim South and Nsawam Adoagyiri. Kwahu East, Kwahu West and Birim South districts were observed to have appalling doctor population ratios. The situation was much highlighted in Table 1 with Kwahu East, Kwahu West and Birim South recording doctor population ratios of zero. Akyem Mansa, Denkyembour, Yilo Krobo and Kwahu Afram Plains South followed closely with poor doctor population ratios, as illustrated in Figure 6. As opposed to Figure 6 where majority of districts with good doctor population ratios were recorded in the Southern sector of the Eastern Region, Figure 7 showed that physician assistant population ratios were better at the Northern Sector, with both Kwahu Afram Plains North and South having the best ratio along with Akwapim South in Southern Eastern Region. East Akim, Lower Manya and the Birim Central Municipal recorded the lowest physician assistant-population ratios.

\section{Discussion}

Majority of the population of the Eastern Region occur in the rural areas. Apart from New Juaben Municipal (93.3\%), Birim Central (67.7\%) and East Akim (59.0\%) that are predominantly urban and Kwahu West (51.2\%), 


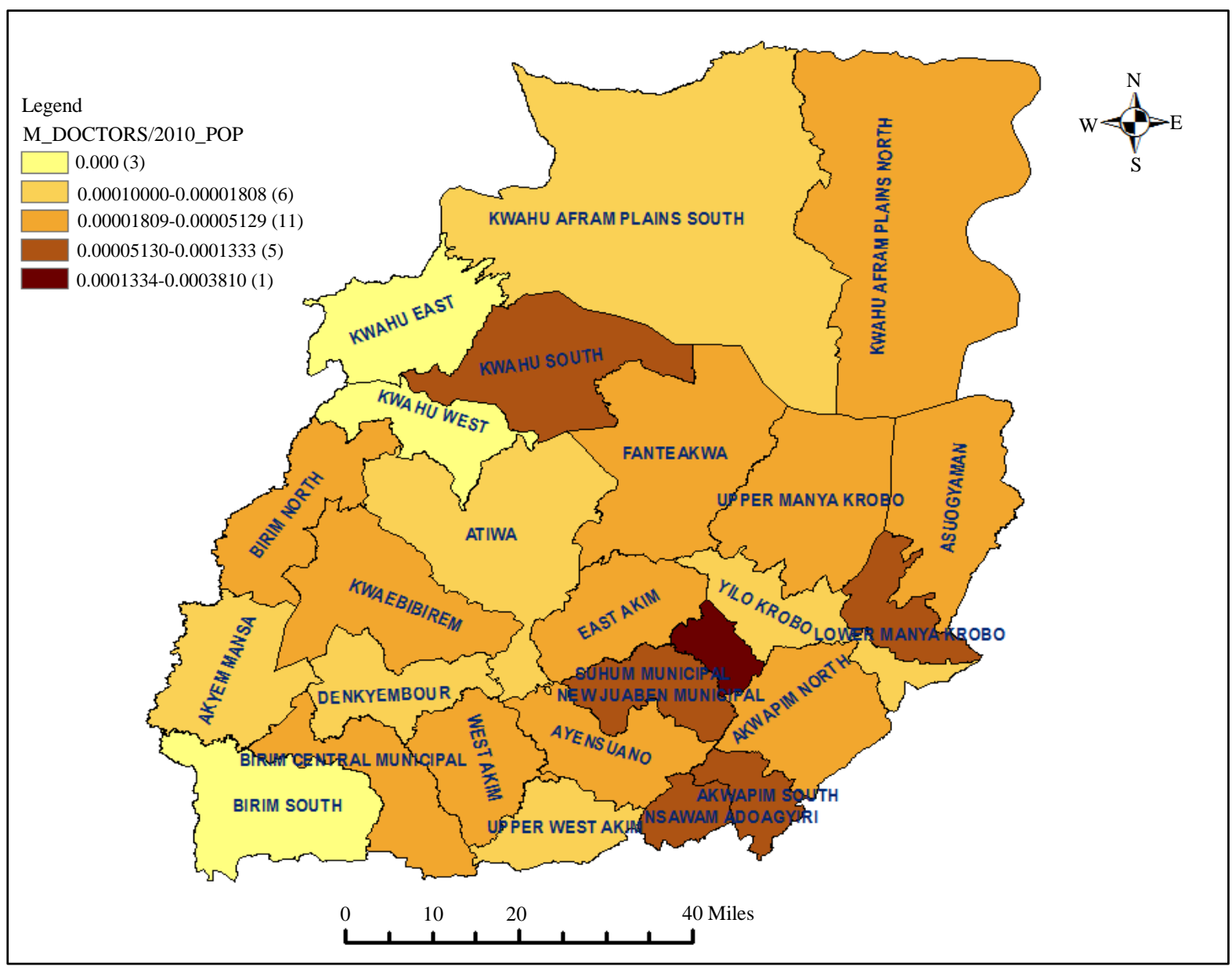

Figure 6. Map displaying distribution of doctors normalized by the population.

[16] which also has a little more than half of the population of the district residing in urban centers, the rest of districts of the region have their populations concentrated in rural areas [17] and hence the likelihood of the problem of access to health facilities [18]. Again, according to discussions with personnel at the directorate, health facilities were more clustered in the urban areas and scattered in the rural areas had a bearing on the access of health facilities on community members in the urban and rural zones.

A two-sample $t$ test as shown in Table 3 confirmed that an increase or decrease in population did not correspond to a change in the number of health facilities. The number of hospitals and clinics especially further demonstrated the persistent imbalance in healthcare facility distribution in the region. The disparity in this distribution could also facilitate corresponding variation in access to healthcare on the part of the population [10]. Districts such as Upper West Akim, Kwahu East, Kwahu Afram Plains South, Ayensuano and Akyem Mansa should be given priority with regard to establishment of hospitals in the Eastern region, especially with Akyem Mansa recording an alarming health facility to population ratio of 19,474:1 as shown in Table 1 . In another development, a thorough observation of Figure 3 and Figure 4 indicated that there was a slight displacement of majority of hospitals and clinics to the southern sector of the Eastern Region. The Kwahu Afram Plains North and South districts were very deficient in terms of hospitals and clinics, particularly Kwahu South which was just created, recording just one clinic. This however is a disturbing situation and contravenes the principle of justice and equity of access to health facilities [2].

To add with, certain districts clearly had poor health facility to population ratio as a result of splitting of existing districts to create new ones, from Table 2, districts such as Kwahu Afram Plains South, Upper West Akim and Ayensuano districts fall within this group and hopefully the health authorities taking key interest in this occurrence will hope to address this issue of addition of new districts without establishing health infrastructure. 


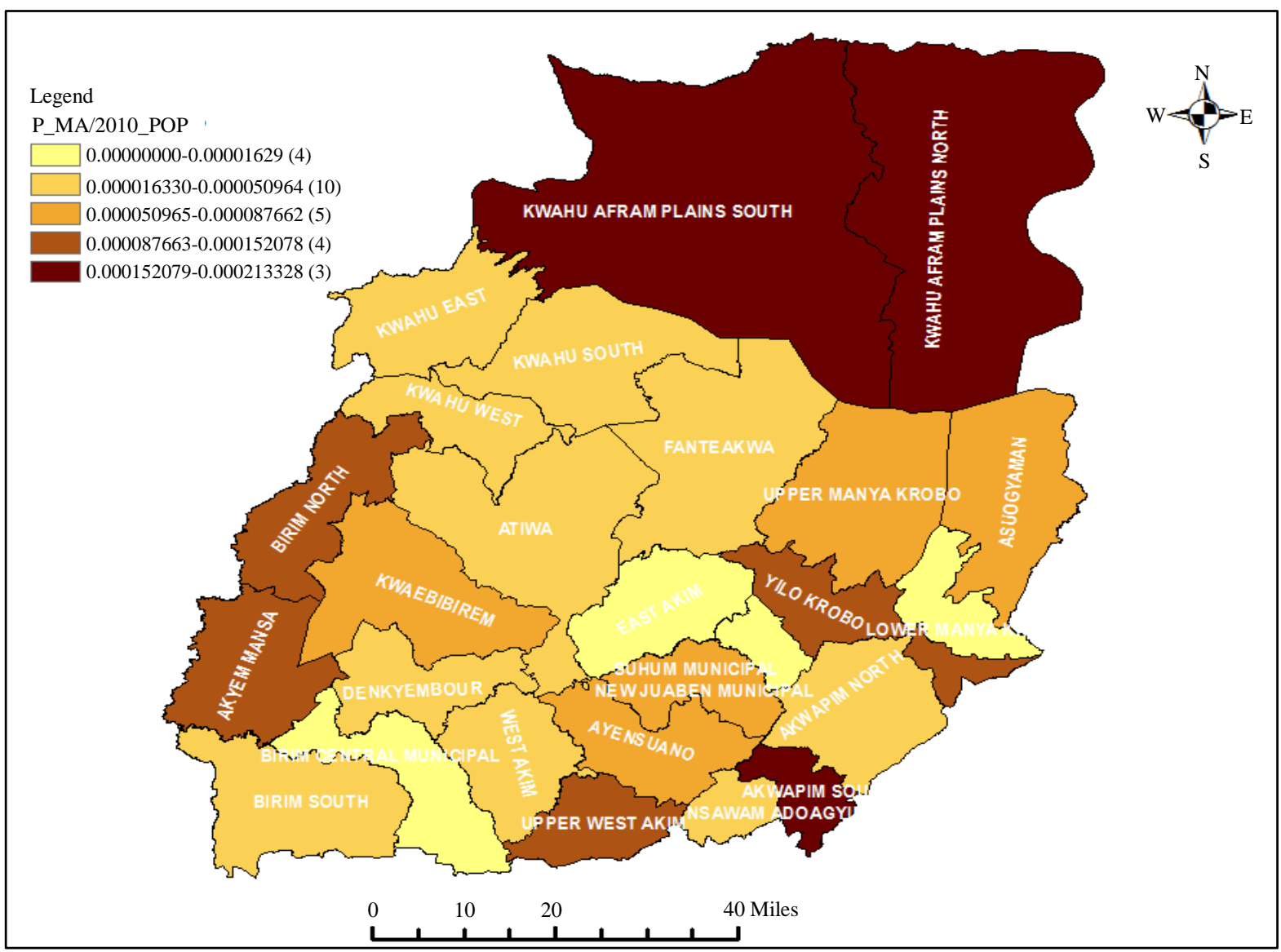

Figure 7. Map displaying distribution of physician assistants normalized by population.

The results of the analysis performed on the health facilities vis-à-vis the population from Table 3 and Table 4 showed that there was no association (as shown in Table 4) neither was there a relationship (as shown in Table 5 and Graph 1) between population and number of health facilities. This development further implies that the health facilities established in various parts of the Eastern region was not done evenly and did not take into account the population distribution of the region. Subsequently, it was observed that some districts were more disadvantaged than others. For example an observation of Table 1 showed that, the Akwapim South district with a population of 37,501 had 17 health facilities present while a district like the newly created Akyem Mansa with a population of about three times that of Akwapim South at 97,374 had only 5 health facilities. The consequence of this is that many individuals in such a vulnerable community cannot access the best of healthcare or at best will resort to healthcare facilities in neighboring districts, which in turn puts pressure with regards to numbers on the facilities of neighboring districts [19].

As indicated in Table 3 in the results section, there was no variation in the number of doctors and physician assistants across the districts/municipalities; this implied that an increase or decrease in population did not correspond to a change in the number of health personnel, as similarly observed in the case of health facilities. The number of doctors and physician assistants especially demonstrated the persistent imbalance in healthcare facility distribution in the region. From Table 1, New Juabeng Municipal recorded the lowest doctor to population ratio of 2625:1, a situation which is primarily as a result of this district being the regional capital and hence expected to be more developed relative to the other districts [20], districts including Denkyembour, Kwahu Afram Plains South, Akyem Mansa and Yilo Krobo recorded alarming doctor to population ratios of over 70,000:1, a phenomenon much higher than the regional doctor to population ratio of 17,438:1. The consequence of this occurrence is such that residents in these districts with a poor doctor to patient ratio are likely to have issues with access to appropriate health services and are either likely to seek alternative forms of health such as traditional medicine or access health services from other neighboring districts [8], a situation that does not augur well for 
Table 1. Summary of population per health facility ratio \& population per health personnel ratio across districts/municipalities.

\begin{tabular}{|c|c|c|c|c|c|c|c|}
\hline District & Population & $\begin{array}{c}\text { Number of health } \\
\text { facilities }\end{array}$ & $\begin{array}{l}\text { Health facility } \\
\text { population ratio }\end{array}$ & DPR & PAPR & MWPR & NPR \\
\hline Akwapim North & 136,483 & 23 & $1: 5934$ & 19498:1 & 12408:1 & 4549:1 & 573:1 \\
\hline Akwapim South & 37,501 & 17 & $1: 2205$ & $7500: 1$ & 18751:1 & 4167:1 & 521:1 \\
\hline Akyem Mansa & 97,374 & 5 & $1: 19,474$ & $97374: 1$ & 97374:1 & 32458:1 & $910: 1$ \\
\hline Asuogyaman & 98,046 & 24 & 1:4085 & 24512:1 & 19609:1 & 8913:1 & 791:1 \\
\hline Atiwa & 110,622 & 12 & $1: 9218$ & 55311:1 & $27656: 1$ & 5531:1 & $675: 1$ \\
\hline Ayensuano & 76,227 & 17 & $1: 4484$ & 25409:1 & 25409:1 & 9528:1 & 1059:1 \\
\hline Birim Central & 144,869 & 40 & $1: 3622$ & $36217: 1$ & 14487:1 & 4527:1 & $696: 1$ \\
\hline Birim North & 78,907 & 28 & $1: 4642$ & 39454:1 & 15781:1 & 5260:1 & $584: 1$ \\
\hline Birim South & 119,767 & 29 & $1: 2818$ & 0 & 39922:1 & 23953:1 & 1186:1 \\
\hline Denkyembour & 78,487 & 17 & $1: 4617$ & 78487:1 & 26162:1 & 19622:1 & 1171:1 \\
\hline East Akim & 167,896 & 19 & $1: 8837$ & 23985:1 & 13991:1 & $4305: 1$ & $770: 1$ \\
\hline Fanteakwa & 108,614 & 14 & $1: 7758$ & 36205:1 & 18102:1 & 6034:1 & $765: 1$ \\
\hline Kwaebibirem & 114,075 & 33 & $1: 3457$ & $22815: 1$ & 28519:1 & 3803:1 & $610: 1$ \\
\hline $\begin{array}{l}\text { Kwahu Afram } \\
\text { Plains North }\end{array}$ & 102,574 & 14 & $1: 7327$ & 51287:1 & 51287:1 & 14653:1 & 1080:1 \\
\hline $\begin{array}{l}\text { Kwahu Afram } \\
\text { Plains South }\end{array}$ & 115,661 & 22 & $1: 5257$ & 115661:1 & 115661:1 & 28915:1 & 1866:1 \\
\hline Kwahu East & 77,125 & 26 & $1: 2966$ & 0 & 25708:1 & 7011:1 & 795:1 \\
\hline Kwahu South & 69,757 & 30 & $1: 2325$ & 11626:1 & 8720:1 & 2250:1 & $375: 1$ \\
\hline Kwahu West & 93,584 & 15 & 1:6239 & 0 & 23396:1 & 8508:1 & 1101:1 \\
\hline $\begin{array}{c}\text { Lower } \\
\text { Manya Krobo }\end{array}$ & 89,246 & 14 & $1: 6374$ & 12749:1 & 8925:1 & 1940:1 & $431: 1$ \\
\hline New Juaben & 183,727 & 43 & $1: 4273$ & $2625: 1$ & 8749:1 & 2112:1 & $510: 1$ \\
\hline $\begin{array}{l}\text { Nsawam } \\
\text { Adoagyiri }\end{array}$ & 86,000 & 34 & $1: 2529$ & 12286:1 & $6615: 1$ & 2324:1 & $443: 1$ \\
\hline Suhum & 91,324 & 27 & 1:3382 & 15221:1 & 13046:1 & $3805: 1$ & $578: 1$ \\
\hline $\begin{array}{c}\text { Upper } \\
\text { Manya Krobo }\end{array}$ & 72,092 & 11 & 1:6554 & 36046:1 & 12015:1 & 4005:1 & $530: 1$ \\
\hline Upper West Akim & 87,051 & 32 & $1: 2720$ & 87051:1 & 0 & 29017:1 & 1036:1 \\
\hline West Akim & 108,298 & 17 & $1: 6370$ & $27075: 1$ & 12033:1 & $5157: 1$ & $737: 1$ \\
\hline Yilo Krobo & 87,847 & 24 & $1: 3660$ & $87847: 1$ & 21962:1 & $5167: 1$ & 813:1 \\
\hline TOTAL & $2,633,154$ & 587 & $1: 4486$ & 17,438:1 & $16,772: 1$ & 4,867:1 & 701:1 \\
\hline
\end{tabular}

Key: TDP—Total District Population, DPR—Population Doctor Ratio, Population—Physician Assistant Population Ratio, MWPR—Populationmidwife ratio, NPR—Population nurse ratio.

Table 2. Changes observed in number of hospitals after addition of districts.

\begin{tabular}{cccc}
\hline Old district name & Number of hospitals before split & New districts formed from old district & Number of hospitals after split \\
\hline Akwapim South & 7 & Akwapim South & 4 \\
& & Nsawam Adoagyiri & 3 \\
Kwahu Afram Plains & 1 & Kwahu Afram Plains North & 0 \\
& & Kwahu Afram Plains South & 1 \\
Suhum/Kraboa/Coaltar & 1 & Suhum & 0 \\
West Akim & \multirow{2}{*}{1} & Ayensuano & 0 \\
& & Upper West Akim & 1 \\
\hline
\end{tabular}


Table 3. Variaton of health facilities \& health personnel across population.

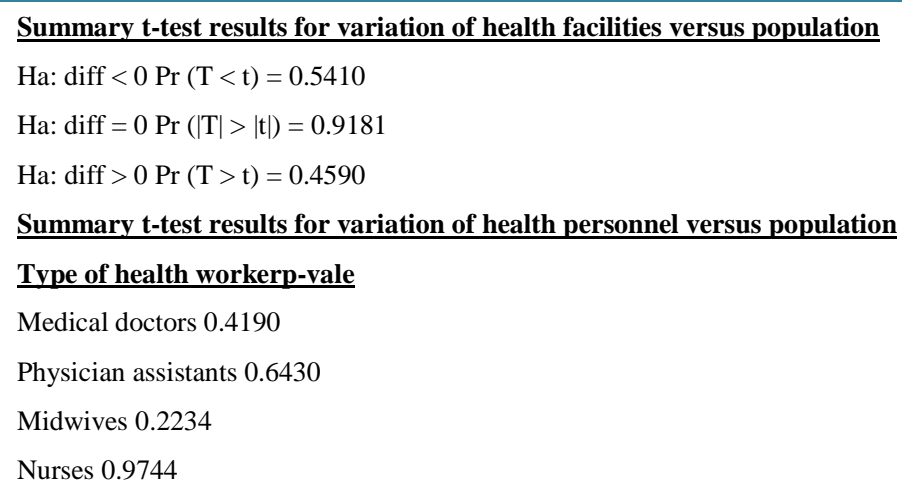

Table 4. Association between health facilities \& health personnel across population.

\begin{tabular}{|c|c|c|}
\hline$\underline{\text { Results for test for }}$ & ociation & pulation and number of health facilities \\
\hline Fisher's exact $=1.00$ & & \\
\hline 1-sided Fisher’s exac & est $=0.5$ & \\
\hline Results for test for & ociation & pulation and number of health workers \\
\hline Type of Health wor & 1-sided & ct testFisher's exact test \\
\hline Medical doctors & 0.598 & 1.000 \\
\hline Physician assistants & 0.677 & 1.000 \\
\hline Midwives & 0.677 & 1.000 \\
\hline Nurses & 0.281 & 0.419 \\
\hline
\end{tabular}

Table 5. Relationship between health facilities/health personnel and population.

\begin{tabular}{|c|c|c|}
\hline Summary of relatio & between $h$ & lities and \\
\hline Pearson Correlation & icient $(r) p$ & \\
\hline 0.2280 & 0.2216 & \\
\hline$\underline{\text { Summary of relatio }}$ & between v & egories 0 \\
\hline Type of Health wor & arson Cor & oefficien \\
\hline Medical doctors & -0.0704 & 0.7324 \\
\hline Physician assistants & -0.1044 & 0.6116 \\
\hline Midwives Nurses & -0.3032 & 0.1321 \\
\hline Nurses & -0.1169 & 0.5695 \\
\hline
\end{tabular}

the principal of equity and social justice in the region [2]. The newly created districts such as Akyem Mansa and Kwahu Afram Plains South and North should be given priority with regards to provision of health workers. As observed in Table 4, there was virtually no association between the number of health personnel in districts and the population. This implied that health personnel were assigned based on all other criteria except the population of the district or municipality in subject. This current situation has a direct impact on disadvantaged districts/ municipalities with alarming health facility to population ratios. A critical observation of Figure 6 indicates that districts such as Kwahu South, Suhum, Akwapim South, Nsawam and Lower Manya Krobo came up second best with regard to the doctor population ratio, this can be attributed to the fact that these districts had lower populations to be addressed by doctors as compared other districts. For example a look at Table 1 showed that both Akwapim South and the Kwaebibirem district have 5 doctors in total; however Akwapim South has a lower population than Kwaebibirem. Akwapim South thus has a lower and better doctor to population ratio than Kwaebibirem because there are more doctors to cater for a lower population as opposed to Kwaebibirem where the same number of medical practitioners are responsible for a much higher population. 


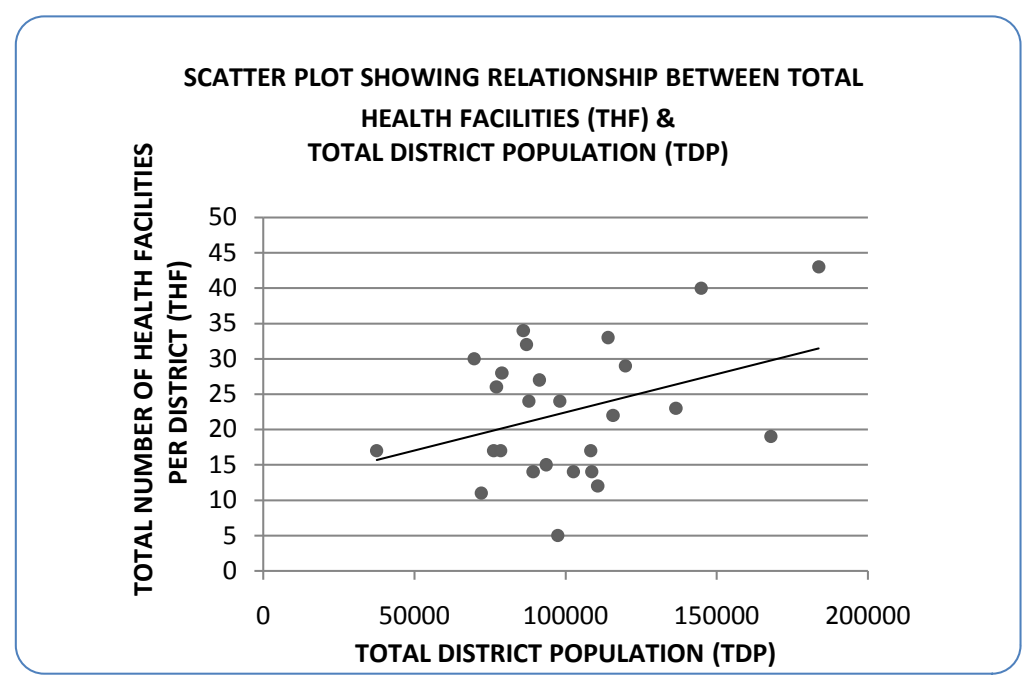

Graph 1. Scatter plot showing relationship between population and number of health facilities.

\section{Conclusion \& Recommendations}

In conclusion, the zero association and the very weak relationship between health facilities and the population as well as that for the health personnel and population has been well established and as a result are not in correspondence with the principle of equity and social justice with regard to access to healthcare services. The observed distribution of health facilities and health personnel was not even and this disparity was well noted in the Kwahu Afram Plains South, Ayensuano, Akyem Mansa, Upper West Akim and Kwahu East districts. The number of hospitals, clinics and CHPS compound in these afore-mentioned districts demonstrated the disparities in the Region and could generate inequalities in the access of population to healthcare. In a similar case, the inequalities in the distribution of health personnel especially the number of doctors were also established. Districts such as Birim South, Kwahu East and Kwahu West recorded zero number of doctors, the newly created districts such as Akyem Mansa and Kwahu Afram Plains South also lacked in terms of number of doctors. This observed deficiency in distribution of health facilities and health personnel has the potential to generate productivity inequalities among residents of the Eastern Region which in turn has a negative effect on the entire development of the region [21].

On the basis of the findings of this study, areas that have been identified as disadvantaged districts should be considered for various intervention strategies. To reduce the regional disparity in health facilities, essential projects such as the improvement of transportation and road infrastructure should be considered in rural areas since poor road infrastructure is an impediment to healthcare accessibility. Again health personnel who set out to work in rural areas should be given extra motivation in terms of monetary gain and better conditions of service; this will help to encourage more health personnel to work in these rural areas. Government should as well put more effort in providing all forms of logistics such as beds, X-ray equipment, electricity, water and other essential medical equipment in these mentioned rural areas to help improve upon the quality of medical care to residents. It is also necessary for government to be more considerate of remote areas that have not exceeded a population threshold for establishment of health facilities, the reason being these rural areas are farther away from the urban zones and hence there is another challenge of the travel time spent in accessing health facilities. Future research interest could spatially explore the distances from the homes of residents in any of the district/municipality to chosen health facilities to assess the effect of distance on access to healthcare.

\section{Acknowledgements}

We acknowledge the willing participation of the subjects in the study. We thank the leadership of the Ghana Health Service office of the Eastern Region, Head of department of Research at the Eastern Regional Health directorate-Ghana (ERHD) Phillipina Schandorf, Officials of the ERHD Department of Health Information; Selase Kennedy Kofitse and Godsway Sackey for data on health facilities and health personnel. We finally acknowl- 
edge the support of the Ensign College of Public Health, Kpong-E/R.

\section{Declaration}

We (Gideon KwartengAcheampong and Stephen Manortey), in our capacity as authors of this manuscript 'a spatial perspective to the distribution of healthcare facilities and health personnel in the Eastern Region of Ghana have duly read and understood the policy on declaration of interests of the Open Access Library (OALib) Journal and herebydeclare that there is no conflict of interest regarding our research. Thank you.

\section{References}

[1] Gauld, R., Blank, R., Burgers, J., Cohen, A.B., Dobrow, M.K., Ikegami, N.K.I., Kwon, S., Luxford, K., Milett, C. and Wendt, C. (2012) The World Health Report 2008—Primary Healthcare: How Wide Is the Gap between Its Agenda and Implementation in 12 High-Income Health Systems? Healthcare Policy, 7, 38-58. http://dx.doi.org/10.12927/hcpol.2013.22778

[2] Whitehead, M. (2000) The Concepts and Principles of Equity and Health. Health Promotion International, 6, $217-228$. http://dx.doi.org/10.1093/heapro/6.3.217

[3] Macinko, J. (2005) Contribution of Primary Care to Health Systems and Health. Milbank Quarterly, 83, 457-502. http://dx.doi.org/10.1111/j.1468-0009.2005.00409.x

[4] Kibon, U.A. and Ahmed, M. (2013) Distribution of Primary Health Care Facilities in Kano Metropolis Using GIS (Geographic Information System). Research Journal of Environmental and Earth Sciences, 5, 167-176.

[5] Abdelhafiz, A. and Abdel-Samea, M. (2013) GIS for Health Services. 1396-1405.

[6] Perry, B. and Gesler, W. (2000) Physical Access to Primary Health Care in Andean Bolivia. Social Science \& Medicine, 50, 1177-1188. http://dx.doi.org/10.1016/S0277-9536(99)00364-0

[7] Atser, J. and Akpan, P. (2009) Spatial Distribution and Accessibility of Health Facilities in Akwa Ibom State, Nigeria. Ethiopian Journal of Environmental Studies and Management, 2, 49-57. http://dx.doi.org/10.4314/ejesm.v2i2.45919

[8] Umar, J. and Bolanle, W. (2015) Locational Distribution of Health Care Facilities in the Rural Area of Ondo State. British Journal of Education, Society \& Behavioural Science, 11, 1-8. http://dx.doi.org/10.9734/BJESBS/2015/17701

[9] Adedayo, A. and Yusuf, R.O. (2012) Health Deprivation in Rural Settlements of Borno State, Nigeria. Journal of Geography and Geology, 4, 52-61. http://dx.doi.org/10.5539/jgg.v4n4p52

[10] Ujoh, F. and Kwaghsende, F. (2014) Analysis of the Spatial Distribution of Health Facilities in Benue State, Nigeria. Public Health Research, 4, 210-218.

[11] Ministry of Local Government and Rural Development (2010) Report of the Committee on District Boundary Disputes Relating to the 2010 Population and Housing Census.

[12] Ghana District Repository (2016) Eastern Region [Online]. http://www.ghanadistricts.com/regional.aspx?r=4

[13] ERHD (2011) Eastern Regional Health Directorate. Annual Health Report.

[14] ERHD (2016) Eastern Regional Health Directorate [Online]. http://erhd.org/cgi/erhd/contact_us.php

[15] (2009) The Health Sector in Ghana: Facts and Figures.

[16] Ghana Statistical Service (2014) 2010 Population \& Housing Census: Tema Metropolitan District Analytical Report. 88.

[17] ERHD (2013) Regional Analytical Report. Koforidua.

[18] Sulemana, A. and Dinye, R.D. (2014) Access to Healthcare in Rural Communities in Ghana: A Study of Some Selected Communities in the Pru District. European Journal of Research in Social Sciences, 2, 122-132.

[19] Ahmad, S. (2012) A GIS Based Investigation of Spatial Accessibility to Health.

[20] Verutes, G.M., Fiocco, M.B., Weeks, J.R. and Coulter, L.L. (2012) Health, Poverty, and Place in Accra, Ghana: Mapping Neighborhoods. Journal of Maps, 8, 369-373. http://dx.doi.org/10.1080/17445647.2012.744365

[21] Francis, B.T. and Godskind, A.A. (2003) An Evaluation of the Spatial Distribution of Healthcare Facilities in Edo State. 
Submit or recommend next manuscript to OALib Journal and we will provide best service for you:

- Publication frequency: Monthly

- 9 subject areas of science, technology and medicine

- Fair and rigorous peer-review system

- Fast publication process

- Article promotion in various social networking sites (LinkedIn, Facebook, Twitter, etc.)

- Maximum dissemination of your research work

Submit Your Paper Online: Click Here to Submit

Contact Us: service@oalib.com 